\title{
How to Improve Outcome of Paediatric Cataract Surgery in Nigeria and Other Developing Countries
}

\author{
OA Dawodu MBBS, FMC (Ophthal), FWACS, FICS \\ Department of Ophthalmology, University of Benin/University of Benin Teaching Hospital, PMB 1111, Benin City, Nigeria
}

\section{SUMMARY}

Paediatric cataract is an important problem all over the world. In developing countries, it is a major cause of childhood blindness resulting in a considerable level of morbidity, economic loss, and social burden. Managing cataracts in children remains a challenge because treatment is often difficult, due to the several ways in which the eyes of children differ from that of adults. The high cost of operative equipment and the uneven world distribution of the manpower that is required make the challenges unique. To assure the best long term outcome for cataract blind children, appropriate paediatric surgical techniques need to be defined and adopted by ophthalmic surgeons in developing countries. This review focuses on issues related to paediatric cataract management that are appropriate and suitable for ophthalmic surgeons in the developing world. It is hoped that adoption of some of the suggested guidelines and recommendations will lead to improved surgical outcome in developing countries, and thereby increase the uptake of the available services.

Key words: paediatric cataract management, developing countries

\section{INTRODUCTION}

Blindness from childhood cataract remains an enormous problem in developing countries ${ }^{1}$ which places a huge social burden on the family and society at large, with resultant economic loss and human morbidity. ${ }^{2,3}$ The management of paediatric cataract differs from that of adults for the following reasons:

- The visual system of the child continues to develop after birth. ${ }^{4}$ The presence of a cataract or other opacities in the ocular media causes deprivation amblyopia when not treated promptly. ${ }^{4}$

- The eye of a normal full term infant is only $65 \%$ of the adult size. ${ }^{5}$ The sclera is thin and translucent, and not as rigid as that of adults. All these make surgery in the infant eye more technically difficult.

- Vision is usually restored soon after uncomplicated cataract surgery in adults. In children, treatment of cataract associated amblyopia is a difficult and demanding step to visual rehabilitation. ${ }^{6}$

- Aphakic glaucoma which could result in change in axial length of the eye is a serious complication in children who have had cataract surgery. ${ }^{1,6,7}$ This does not occur in adults.

- Other complications of cataract surgery such as inflammatory sequelae, secondary membranes, changing refractive state and retinal detachment are more common and could be more severe and more difficult to manage in children. ${ }^{8,9}$

Despite the challenges in the management of paediatric cataracts, the visual outcomes in paediatric cataract surgery are continually improving due to better understanding of the sensitive period for the development and reversal of amblyopia, timing of cataract removal, and improvement in surgical techniques. ${ }^{10,}{ }^{11}$ Early correction of aphakic refractive error is one of the most critical components of effective management of paediatric cataracts. With improved surgical equipment and techniques, the acceptable age at which intraocular lenses can be implanted is becoming progressively lower. ${ }^{12}$ In developed countries, intraocular lens implantation is now common in children across the entire age spectrum, including infants less than a year old. ${ }^{13}$

The management of paediatric cataracts is particularly challenging in developing countries due to lack of trained personnel to deal with the huge numbers of paediatric cataracts, as well as limitations in available equipment and other support services such as trained paediatric anaesthetists, orthoptists, ${ }^{1,14}$ etc.

The aim of this paper is to highlight ways of improving the outcome of paediatric cataract surgery in Nigeria and other developing countries and meeting the challenges posed by the present limitations.

\section{AGNITUDE OF THE PROBLEM OF PAEDIATRIC CATARACTS IN DEVELOPING COUNTRIES}

Blindness rates are about ten times higher in developing countries than developed countries. Of the 1.5 million blind children in the world, 1.3 million live in developing countries of Asia and Africa where blindness prevalence rates can be as high as 1.5 per 1000 population. ${ }^{15-23}$

A study of the distribution of paediatric ophthal-mologists in the United States of America showed an average of 3 to 4 paediatric ophthalmologists to one million persons. ${ }^{24}$ Trained paediatric ophthalmologists are very few in developing countries. The exact number in Africa is unknown. In Nigeria, the number of trained paediatric ophthalmologists is less than twenty, ${ }^{25}$ providing services to the over 150 million population. ${ }^{26}$ Support services from other personnel required for the team approach essential for pediatric ophthalmology service delivery, such as well trained paediatric 
anaesthetists, orthoptists, etc. are lacking. ${ }^{14}$ Also, necessary equipment such as automated vitreous cutters, hand-held slit lamps, electrophysiological units and investigative tools such as hand-held keratometers, A- Scan, B-Scan ultrasonography, fundus camera, optical coherence tomography (OCT), and Retcam, are not available in most centres in developing countries. This limits what can be done when there is a need for further investigations in cases where cataract coexists with other ocular anomalies. Common developmental defects that can coexist with congenital cataracts include: microphthalmia, retinal lesions, optic atrophy, glaucoma, persistent hyaloid vessels, nystagmus and strabismus. ${ }^{14}$

Routine eye examination of all newborn babies to detect any abnormality that would prevent the development of good vision is yet to be implemented in developing countries. The simple red reflex test, whereby the pupil of the newborn is examined for a red reflex, helps to pick up abnormalities such as opacities in the ocular media and the dreaded intraocular tumour in children - retinoblastoma. Other congenital eye disorders/malformation such as Peter's anomaly, Rieger's anomaly, aniridia, etc. can be detected early and referred for appropriate treatment. In Nigeria as in many other developing countries, where children are still being delivered outside the hospital setting, in health centres, maternity homes and some at home by traditional birth attendants (TBA), it is not feasible to get them examined by paediatricians.

The manpower required to deal with the large population of children in developing countries is also lacking. Children below the age of 15 years make up about $50 \%$ of the entire population in the developing world. ${ }^{27}$ Ophthalmologists are few and usually reside in the cities with little or no coverage of the rural areas. This maldistribution of personnel results in a huge burden of disease among the rural dwellers. In a typical clinic setting, from the author's experience, it is not unusual to have a child who was born with congenital cataract presenting for the first time at the age of 12 years or older. ${ }^{28}$ Such late presentation gives rise to poor visual results due to deprivation amblyopia. This greatly reduces the chance of reasonable improvement in visual acuity when the surgery is eventually done. Even when they present early, some would decline surgery based on the premise that the child is too young to have surgery. Therefore, the opportunity of early surgery and amblyopia prevention is missed.

\section{REVIEW OF PAEDIATRIC CATARACT SURGICAL OUTCOME IN DEVELOPED AND DEVELOPING COUNTRIES}

A review of the outcome of paediatric cataract surgery in developed countries shows good visual outcome in a high proportion of cases. Crouch et $\mathrm{al}^{29}(\mathrm{~N}=52)$ reported an improvement in vision to 20/30 in $95 \%$ of patients, while Brady et al. ${ }^{30}(\mathrm{~N}=45)$ reported an improvement of $20 / 40$ in $100 \%$ of patients. Wilson et $\mathrm{al}^{31,32}$ $(\mathrm{N}=144)$ and Plager et $\mathrm{a}^{33}(\mathrm{~N}=79)$ reported an improvement of $20 / 40$ in $79 \%$ of patients.

There is a dearth of literature on outcomes of paediatric cataract surgeries in developing countries. Studies from Nepal, India, and Pakistan show a range of $40.5 \%-67 \%$ of patients whose vision improved to $6 / 18(20 / 60)$ or better. ${ }^{1,14,34}$, The author is not aware of any published data from Nigeria.

The reason for the disparity in outcome of cataract surgery in developed and developing nations can be due to several factors which include but are not limited to early presentation, availability of IOL calculation equipment, better equipment such high resolution microscopes, phacoemulsification machines, vitreous cutters, foldable lenses, resulting in better surgical techniques in developed countries. Also, there is a wider range of methods of aphakia correction as well as improved methods of amblyopia treatment. In the Nepal study, only older children had IOL power calculation due to lack of facilities to do the calculations in younger children and babies. ${ }^{14}$

Some surgeons in developing countries still do either needling, or needling and aspiration or extracapsular cataract extraction (ECCE) and intraocular lens implant (IOL) with or without primary posterior capsulotomy (PPC). With any of these procedures, there is no guaranty of the clarity of the media since the vitreous face can serve as a scaffold on which lens epithelium can grow. ${ }^{1}$ As a result, the long-term visual outcome is negatively affected by opacification of the posterior capsule post operatively.

Extracapsular cataract surgery, primary posterior capsulotomy, anterior vitrectomy, and intraocular lens implant provide the best chance of a long term clear visual axis in children between the age of $2-8$ years. ${ }^{1}$ From the age of 8 years, primary posterior capsulotomy is still recommended, although anterior vitrectomy is optional. Below the age of 2 years, the use of intraocular lens implant is controversial. ${ }^{36}$ Implantation of an IOL during cataract surgery in the developing world seems to be a practical option even in infants, since contact lenses which are used for visual rehabilitation in this age group in developed countries are less suitable in these settings.

\section{THE W AY FORWARD}

The optimal standard of treatment of paediatric cataract in the developed world is lensectomy (ECCE with primary posterior capsulotomy and anterior vitrectomy) with IOL implant beyond infancy. Contact lenses are generally used for infants. There should be consistent efforts to attain this standard in developing countries.

Due to the very early surgical intervention in developed countries (newborns with cataract have lensectomy as early as one or two weeks after birth), followed by contact lens correction of the resulting aphakia, good results are the norm. This allows very early visual rehabilitation and gives the opportunity for amblyopia prevention and treatment. The result is that children born with cataracts in developed countries have a high chance of getting good binocular vision when surgery is done early and the parents comply with the visual rehabilitation regimen. Though contact lens usage is not very practicable for a wide segment of the society in developing countries due to cost and the tedious disinfection regimen required, aphakic glasses could be used in infancy and secondary lens implant done at a later age of about 2 years or above.

The insertion of the polymethyl methacrylate (PMMA) through a scleral tunnel incision is probably the most practicable for now. This is because the ophthalmologists trained in the developing countries are already familiar with the scleral tunnel technique needed for SICS. The PMMA lenses can be inserted through a scleral tunnel with application of one or two stitches to secure the 
wound. They are cheap and affordable as opposed to the foldable lenses. Foldable intraocular lenses (IOLs) made from hydrophilic acrylic biomaterial are commonly implanted in the USA, the United Kingdom, Canada and other developed countries but are prohibitively expensive in developing countries (more than $\$ 100) .{ }^{1}$

Simultaneous cataract surgery for children, under general anaesthesia, should be strongly considered in developing countries due to the difficulties of getting general anaesthesia in this setting and the cost. Though this is not done in industrialized nations due to the risk of bilateral blinding endolphthalmitis, the advantages could be said to outweigh this small risk in some settings. This risk can be minimized by using separate sterile packs and eye drops for the second eye.

Very few centres in developing countries have the facilities for phacoemulsification, which is the standard procedure for adult cataracts in developed countries. In Nigeria, a few private hospitals are carrying out cataract surgery using the phacoemulsification method. However, only a limited number of the few trained paediatric ophthalmologists have facilities for lensectomy which is the surgery of choice in children. Childhood cataracts are being treated surgically by extra capsular cataract extraction with intraocular lens implant. This invariably carries the risk of posterior capsule opacification in a lot of the cases. Very few centres have the YAG laser necessary to deal with posterior capsule opacification. Some ophthalmologists do a primary posterior capsulotomy to prevent vision loss from posterior capsule opacification.

Compared to what obtains in developed countries, children with cataract in developing countries present to the ophthalmologist very late. The age at presentation can range from a few months old to adolescence. Some of them with dense cataracts would also have developed dense amblyopia with nystagmus. A massive awareness programme needs to be launched to educate mothers about the importance of consulting an ophthalmologist for all cases if a white spot is seen behind a child's pupil. Any sudden development of an eye turn (strabismus) also needs to be checked to rule out a posterior segment cause such as retinoblastoma or a neuroophthalmological problem.

Three quarters of the world's blind children live in developing countries. ${ }^{3}$ With the high burden of disease and low vision/blindness, a lot needs to be done to reverse the trend.

\section{RECOMMENDATIONS}

1. Efforts should be intensified in the promotion of good eye health, by putting in place preventive measures such as:

- Screening of newborns for ocular defects to ensure early intervention. This should be done by other cadres of health care providers such as traditional birth attendants, midwives, nurses, general practitioners and paediatricians who should receive some training to guarantee effectiveness.

- Improving immunization coverage to reduce measles, rubella and other ailments preventable by immunization

2. Equipping eye care workers adequately to provide standard and effective curative services. In advocating improvement in services in developing nations, there should be a step by step improvement of what is already available in a centre. Appropriate technology need to be provided to ensure sustenance. There is the need for training of the personnel on ground on the use of more modern equipment before they are purchased. Foreign agencies from developed countries that are willing to contribute to development of eye care in developing nations should be encouraged to lay more emphasis on training of local ophthalmologists, and donation of new/used equipment rather than carrying out eye camps. These eye camps only succeed in helping a few patients regain vision whereas a lot more benefit could be obtained by teaching local ophthalmologists improved surgical techniques which will empower them to treat a much larger number in their years of practice.

3. There is a need to train other cadres of health care providers on how to identify cataracts and other conditions that can prevent a red reflex in the pupil of the newborn and refer them to hospitals where they can be examined by paediatricians /ophthalmologists.

4. Due to lack of resources, special regional hospitals should be established and equipped with facilities such as keratometers, ultrasonography machines, vitrectomy machines, anaesthesia machines, electrophysiology units and staffed adequately with trained personnel to deal with paediatric eye diseases. A good referral system should be in place to ensure that children who need this service get access. This is only possible if the services are subsidized by government since the running cost of such a centre will be high, and insurance coverage of the population that need it most is minimal or non existent.

5. Regular training and retraining of staff manning these regional hospitals in collaboration with staff of paediatric ophthalmology centres in developed countries. Exchange programmes could be worked out to the mutual benefit of both institutions.

6. Rehabilitation measures should also be provided for those who, in spite of adequate treatment, cannot regain useful vision.

A lot can be achieved in improving paediatric ophthalmology services in developing countries through advocacy by health care professionals. There is a need to reach out to non governmental agencies since government expenditure on health in most poor countries is at best, inadequate. Adequate planning and development of strategies is needed to ensure that service delivery is not unduly compromised for the teaming population of children in the developing world. There is no doubt that improvement in surgical techniques which will result in better surgical outcome will have a positive impact on the uptake of services.

\section{REFERENCES}

1. Wilson ME, Pandey SK, Thakur J. Paediatric cataract blindness in the developing world: surgical techniques and intraocular lenses in the new millennium. Br J Ophthalmol 2003; 87(1):14-19.

2. Moriarty BJ. Childhood blindness in Jamaica. Br J Ophthalmol 
1988; 72: 65-7.

3. Waddell KM. Childhood blindness and low vision in Uganda. Eye 1998; 12: 184-92.

4. Liesegang TJ, Skuta GL, Cantor LB. Basic and Clinical Science Course. Section 6. American Academy of Ophthalmology; 20072008: 50.

5. Olitsky SE, Nelson LB. Disorders of the eye. In Behrman R E, Kliegmam R M, Jenson H B. Nelson Textbook of Paediatrics $17^{\text {th }}$ Edition. Saunders Philadelphia., p.2083.

6. Ledoux DM, Travedi RH, Wilson ME, Payne JF. Pediatric cataract extraction with intraocular lens implantation: Visual acuity outcome when measured at age four years and older. Journal of American Academy of Pediatric Ophthalmology and Strabismus 2007; 11(3): 218-224.

7. Trevedi RH, Wilson ME. Changes in interocular axial length after pediatric cataract surgery. Journal of American Academy of Pediatric Ophthalmology and Strabismus 2007; 11 (3): 225-229.

8. Gilbert C, Foster A. Childhood blindness in the control of vision 2020-the right to sight. Bull World Health Organ 2001; 79: 227-32.

9. Hosal B. Risk factors for secondary membrane formation after removal of pediatric cataract. J Cataract Refract Surg 2002; 28: 302-309.

10. Cheng KP, Hiles DA, Biglan AW. Pettapiece MC. Visual results after early surgical treatment of unilateral congenital cataracts. Ophthalmology 1991; 94: 441-9.

11. Kugelberg U. Visual acuity following treatment of bilateral congenital cataracts. Doc Ophthalmol 1992; 82:211-5.

12. Wilson ME. Intraocular lens implantation: has it become the standard of care for children? (Editorial). Ophthalmology 1996; 103: 1719-20.

13. Lambert SR, Lynn M, Drews-Botsch C, DuBois L, Wilson ME, Plager DA et al. Intraocular lens implantation during infancy: Perception of parents and American Academy of Ophthalmology and Strabismus members. J AAPOS 2003; 7: 400-5.

14. Thakur J, Reddy H, Wilson ME, Paudyal G, Gurung R, Thapa S, Tabin G, Ruit S. Pediatric cataract surgery in Nepal. J Cataract Refract Surg 2004;30:1629-1635.

15. Cunningham ET. Lietman TM, Whitcher JP. Blindness: a global priority for the twenty-first century. Bull World Health Organ 2001; 79:180.

16. Hoyt CS, Good WV. The many challenges of childhood blindness. Br J Ophthal 2001; 85: 1145-6.

17. Steinkuller PG, Du L, Gilbert C, et al. Childhood blindness. J AAPOS 1999; 3: 26-32.

18. O'Sullivian J, Gilbert C, Foster A. The causes of childhood blindness in South Africa. S Afr Med J 1997; 87: 1691-5.

19. Foster A. Cataract and "Vision 2020- the right to sight" initiative. Br J Ophthalmol 2001; 85: 635-7.

20. Foster A, Gilbert C, Rahi J. Epidemiology of cataract in childhood: a global perspective. J Cataract and Refractive Surgery 1997; 23: 601-4.

21. Rahi JS , Gilbert CE, Foster A et al. Measuring the burden of childhood blindness. B J Ophthalmol 1999; 83: 387

22. Foster A. Childhood blindness in India and Sri Lanka. Indian J Ophthalmol 1996; 44: 57-60.

23. Gogate $P$, Gilbert $C$. Blindness in Children: a world perspective. Community Eye Health Journal 2007; 20: 33-4.

24. Estes R, Estes D, West C, Zobal-Ratner J, Droster P, Simon P. The American Association of Pediatric Ophthalmology and Strabismus workforce distribution project. JAAPOS 2007; 11(4): 325-29.

25. Personal communication with members of pediatric ophthalmology working group (POWG) of the Ophthalmological Society of Nigeria.

26. National Population Commission (2006 census figures)

27. Thylefors B. Cataract is a global health problem. Ophthalmic Res 1999; 31:143-60

28. Dawodu OA, Dawodu SO. Congenital Cataracts in Multiple Siblings of a Monogamous Family. Nigerian Journal of Clinical Practice 2000; (2) 85-88.

29. Couch ER, Crouch ER, Pressman SH, Prospective analysis of pediatric pseudophakia: Myopic shift and post operative outcomes. JAAPOS 2002; 6: 277-82.

30. Brady KM, Atkinson CS, Kilty LA, Hiles DA. Cataract Surgery and intraocular lens implantation in children. Am J Ophthalmol 1995; 120: 1-9.

31. Wilson ME, Bluestein EC, Wang XH Current trends in the use of intraocular lenses in children. J Cataract Refract Surg 1994; 20: 579-83.

32. Ledoux DM, Rupal HT, Wilson E, Payne JF. Pediatric cataract extraction with intraocular lens implantation: Visual acuity outcome when measured at age four years or older. JAAPOS 2007; 11 (3) 218-24

33. Plager DA, Lipsky SN, Snyder SK, Sprunger DT, Ellis FD, Sondhi N. Capsular management and refractive error in pediatric intraocular lenses. Ophthalmology 1997; 104: 600-7.

34. Sharma N. Complications of pediatric cataract surgery and intraocular lens implantation Journal of Cataract \& Refractive Surgery 1999; 25(12): 1585-1588.

35. Zwaan J, Mullaney PB, Awad A, Al Mesfer S, Wheeler DT. Pediatric intraocular lens implantation: Surgical results and complications in more than 300 patients. Ophthalmology 1998; 105(1) 112-9.

36. Basti S, Ravishankar U, Gupta S. Result of a prospective evaluation of three methods of management of pediatric cataracts. Ophthalmology 1996; 103(5) 713-20. 